\title{
Sistem Pemrosesan Transaksi Pada Toko Bangunan Berbasis Web Dengan PHP dan MySQL
}

\author{
Rizky Gelar Maliq, Dr. R. Rizal Isnanto,S.T., M.M., M.T., Ike Pertiwi Windasari, S.T., M.T. \\ Program Studi Sistem Komputer, Fakultas Teknik, Universitas Diponegoro, \\ Jln. Prof. Sudharto, Tembalang, Semarang, Indonesia \\ email : riskygelarmaliq@gmail.com
}

\begin{abstract}
Building supply store is a business entity engaged in the sale of construction materials for the building. Where there are still use the transaction data were administrative in bookkeeping way, so it takes a long time to figure out the sale and purchase transactions. Therefore, the author here takes issue in the sale and purchase itself.

Transaction processing systems created using PHP programming language and MySQL database. System where this information can help in recording the transaction in the building supply store. In addition to recording can also be used for the preparation of monthly reports .

The expected result from design of this transaction processing systems is to build a computerized information system to facilitate the operator in the transaction. With this expected to improve customer service so well that the presentation of information in a relatively quick and accurate transactions. Moreover, it can accelerate the collection of goods to see inventory and preparing reports .
\end{abstract}

Key Terms: Transaction processing systems, transaction, PHP, MYSQL.

\section{PENDAhUluan}

$\mathrm{P}$ ERKEMBANGAN teknologi informasi di era globalisasi ini telah mengalami perubahan yang cukup pesat sehingga dapat mempengaruhi aspek kehidupan. Hal ini dapat kita lihat dengan banyaknya perusahaan atau badan usaha atau pun instansi tidak lepas dari pengaruh teknologi dalam kegiatannya terutama teknologi komputer membuat suatu pekerjaan lebih menjadi efektif dan efesien.

Dalam hal ini di toko bahan bangunan Sinar Mas adalah salah satu badan usaha yang bergerak di ritel yang melayani konsumen dalam penjualan bahan bangunan. Pengelolaan datanya masih menggunakan cara pembukuan, sehingga pada saat konsumen melakukan transaksi membutuhkan waktu yang cukup lama termasuk juga untuk transaksi dengan distributor (pembelian). Selain itu pada toko bahan bangunan Sinar Mas masih menggunakan cara pembukuan untuk pembuatan laporan bulana maupun laporan harian. Hal ini dikarenakan pelayanan konsumen belum terkomputerisasi. Oleh sebab itu, penulis di sini mengambil masalah ini. Selain itu dapat mempercepat pendataan dalam transaksi jual beli dan pelunasan jual maupun beli.

Dengan ini di harapkan dapat membantu dalam meningkatkan pelayanan kepada konsumen maupun distributor serta untuk menyimpan data atau dokumen penting lainnya yang harus di simpan dengan baik sehingga dalam penyajian informasi relatif cepat dan akurat.

\section{TINJAUAN PUSTAKA}

\section{A. Sistem Pemrosesan Transaksi}

Menurut Hanif al Fatta (2007), sistem pemrosesan transaksi (transaction processing system-TPS) adalah sistem informasi terkomputerisasi yang dikembangkan untuk memproses sejumlah besar data transaksi bisnis rutin untuk menghasilkan informasi keuangan.

\section{B. Kualitas Sistem Pemrosesan Transaksi}

Untuk mengetahui bahwa TPS memiliki kualitas yang baik maka menurut Turban et al (2008), sebuah program aplikasi TPS harus memiliki karakter sebagai berikut:

1. Program dapat melakukan fungsinya dengan benar dan lengkap.Kriteria ini dapat terwujudkan jika sebuah TPS dapat melakukan fungsi-fungsi berikut, yakni:

a. Menangkap data dari setiap transaksi

b. Mengotomatisasi pengamanan data transaksi

c. Memverifikasi transaksi untuk diterima dan ditolak

d. Menyimpan transaksi yang telah diverifikasi

e. Menghasilkan laporan

Jadi pada dasarnya fungsi sebuah TPS adalah untuk mengumpulkan, menyimpan, memproses data transaksi kemudian menyajikan hasil pemrosesan tersebut dalam bentuk laporan keuangan maupun laporan-laporan kebutuhan lainnya. Untuk itu, program aplikasi yang digunakan dalam sebuah TPS harus dapat mendukung jalannya fungsi-fungsi tersebut secara baik dan tepat waktu (Turban et al, 2008).

2. Program memiliki user interface yang berkualitas tinggi. Tujuan sebuah user interface adalah mengkomunikasikan fitur-fitur program aplikasi yang tersedia agar user untuk memahami dan menggunakan sistem dengan mudah (Sommerville, 2001). Berikut ini prinsip-prinsip user interface yang berkualitas:

a. Mudah dikenali; software harus mengggunakan tools istilah dan konsep yang mudah dipahami user.

b. Mudah digunakan; tingkat dimana seseorang meyakini bahwa penggunaan sistem informasi adalah mudah dan tidak memerlukan usaha keras dari pemakai dalam menggunakannya.

c. Recover ability; software dapat mengkonfirmasi aksi yang merusak serta menyediakan fasilitas pembatalan.

Pemodelan proses adalah cara formal untuk menggambarkan bagaimana bisnis beroperasi. Mengilustrasikan aktivitas-aktivitas yang dilakukan dan 
bagaimana data berpindah di antara aktivitas-aktivitas itu. Salah satu cara untuk merepresentasikan proses model adalah dengan cara Data Flow Diagram (DFD).

\section{ANALISIS DAN PERANCANGAN SISTEM}

\section{A. Analisis Kebutuhan Sistem}

Sistem yang dibuat seringkali tidak sesuai dengan keinginan dari pengguna sistem yang memungkinkan terjadi kesalahan dan ketidak sepahaman. Hal ini biasa terjadi jika dalam pembuatan sebuah sistem tidak diawali dengan analisis kebutuhan yang mendasar dan rinci. Analisis kebutuhan dapat dilakukan melalui wawancara dengan pihak-pihak terkait dan pengamatan dari lingkungan di mana sistem akan dibangun.

1. Deskripsi Umum

Demi mempermudah dan menunjang kinerja dari Toko Sinar Mas, diharapkan program ini dapat :

a. Mempermudah admin (pemilik toko) untuk melakukan transaksi pembelian, transaksi penjualan, dan melihat stok barang membuat laporan untuk Toko Sinar Mas.

b. Mempermudah superkasir dan kasir dalam melakukan transaksi pembelian, dan penjualan.

c. Mempermudah karyawan dalam melayani konsumen untuk transaksi penjualan.

d. Mempermudah karyawan dalam melayani supplier untuk transaksi pembelian.

e. Mempermudah admin untuk membuat laporan pembelian, penjualan dan stok barang dalam bentuk PDF dan Word.

\section{B. Analisis}

Untuk memahami sifat dan fungsi perangkat lunak yang akan dibangun, analisis dari sistem itu sendiri sangat diperlukan, terutama dalam memahami domain informasi dan tingkah laku yang diperlukan yang mengacu pada tahap sebelumnya yaitu analisis kebutuhan.

Berdasarkan tahapan dari deskripsi umum sebelumnya, dalam pembuatan sistem informasi ini ada beberapa tingkatan pengguna, yang dapat dibagi menjadi tiga tingkatan, yaitu :

1. Admin

Admin adalah tingkatan tertinggi dalam sistem dan memiliki wewenang untuk :

a. Menambahkan, merubah dan menghapus tabel kategori barang, barang, pengguna, supplier.

b. Melukan transaksi pembelian dan transaksi penjualan beserta menghapusnya.

c. Mencetak laporan barang, penjualan dan pembelian.

\section{Super Kasir}

Super Kasir merupakan tingkatan kasir yang memiliki akses lebih dan memiliki wewenang untuk:

a. Menambahkan, merubah dan menghapus tabel kategori barang, barang, supplier.

b. Melakukan transaksi pembelian dan transaksi penjualan.

3. Kasir

Kasir adalah tingkatan yang mempunyai wewenang :

a. Melakukan transaksi penjualan.

\section{Perancangan Data}

Tahap ketiga adalah tahap perancangan / desain perangkat lunak yang merupakan proses multi langkah dan berfokus pada beberata atribut perangkat lunak. Proses ini berdasarkan dari analisa sebelumnya sehingga menciptakan sebuah rancangan yang sesuai dengan kebutuhan dari pihak instansi terkait. Dalam perancangan model perangkat lunak ini, digunakan pemodelan terstruktur yaitu Data Flow Diagram (DFD) dan Entity Relationship Diagram (ERD), metode ini menyajikan data dengan menggunakan entitas dan hubungan antar tabel.

\section{Data Flow Diagram (DFD)}

Dalam langkah ini dilakukan penentuan entitas-entitas, baik entitas dalam maupun maupun entitas luar, data yang mengalir serta prosedur yang terlibat bisa dilakukan oleh masing-masing entitas.

a. Perancangan DFD

DFD merupakan diagram aliran data yang menggambarkan bagaimana data diproses oleh sistem. Selain itu DFD menggambarkan notasi-notasi aliran data di dalam sistem. Proses perancangan dimulai dengan pembuatan bagan alir sistem atau yang disebut dengan diagram konteks. Diagram konteks menggambarkan suatu sistem secara umum. Diagram konteks ini juga menggambarkan bahwa sistem pemrosesan transaksi berbasis web dan mysql mempunyai tiga pengguna sistem yaitu : Admin, Super Kasir dan Kasir.

Admin adalah orang yang mempunyai kewenangan penuh atas sistem, bertugas mengelola hak akses pada sistem, dan menghasilkan transaksi. Superkasir adalah kasir yang mendapat akses lebih dari kasir bisa, Sedangkan kasir hanya bisa melakukan transaksi penjualan. Untuk diagram konteksnya dapat dilihat pada Gambar 1.

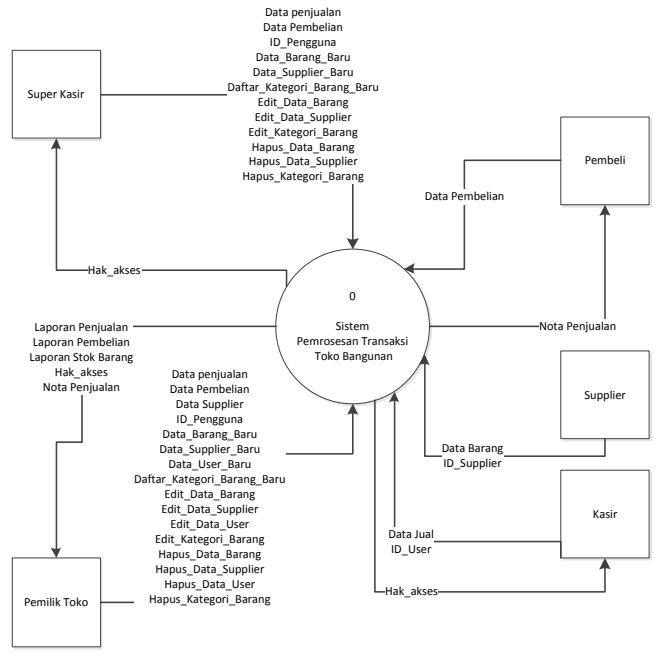

Gambar 1. Diagram konteks / DFD level 0

DFD level 1 dapat dilihat pada Gambar 2.

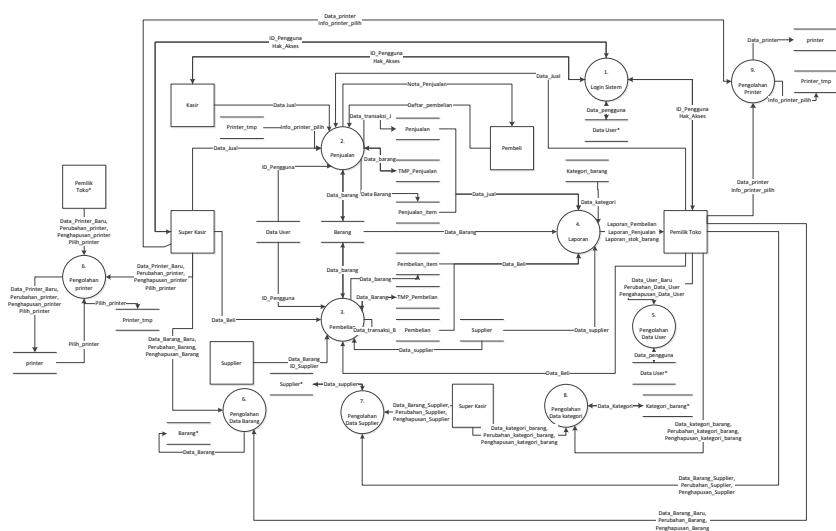

Gambar 2. Diagram konteks / DFD level 0

2. Perancangan Data

Perancangan data terdiri dari diagram skema dan struktur tabel yang terdapat pada ERD dari sistem pemrosesan 
transaksi pada toko bangunan berbasis web yang telah dirancang sebelumnya. . Entitas yang terlibat dalam transaksi pembelian dan penjualan adalah entitas barang, tmp_pembelian, pembelian_item, pembelian, penjualan, penjualan_item, dan penjualan_tmp. ERD yang digunakan untuk memperlihatkan hubungan antar entitas dalam sistem pemrosesan transaksi ini di tunjukkan pada Gambar 3 sebagai berikut.

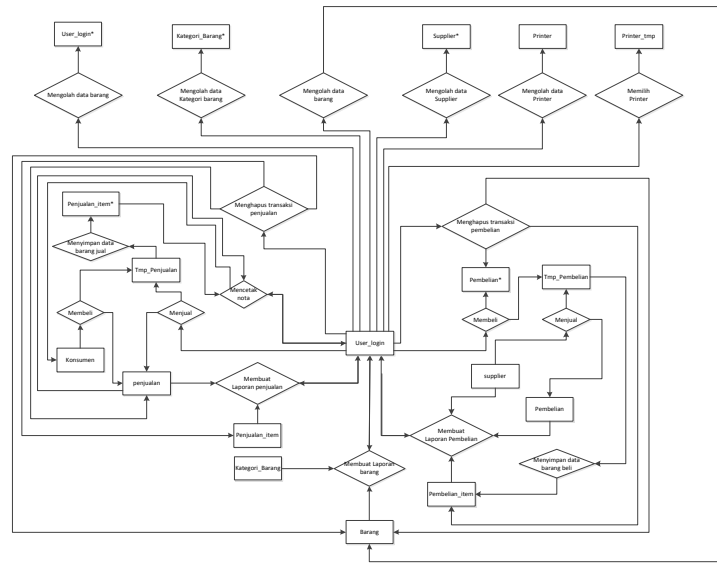

Gambar 3. Entity-Relationship Diagram (ERD)

3. Perancangan Menu

Perancangan menu bertujuan untuk memberikan gambaran tentang sistem pemrosesan transaksi yang akan dibangun Perancangan sistem pemrosesan transaksi toko bangunan yang akan dibangun.

a. Menu Kasir

Pada gambar 4, ditampilkan menu untuk kasir.

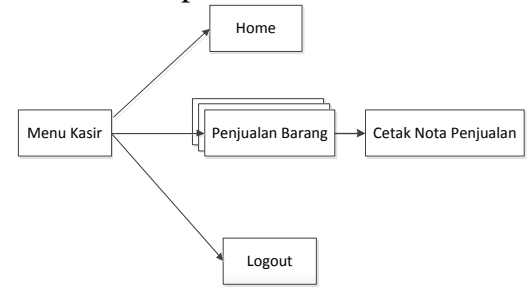

Gambar 4. Pembagian menu kasir

b. Menu Super Kasir

Pada gambar 5, berikut ditampilkan menu yang akan didapatkan oleh super kasir.

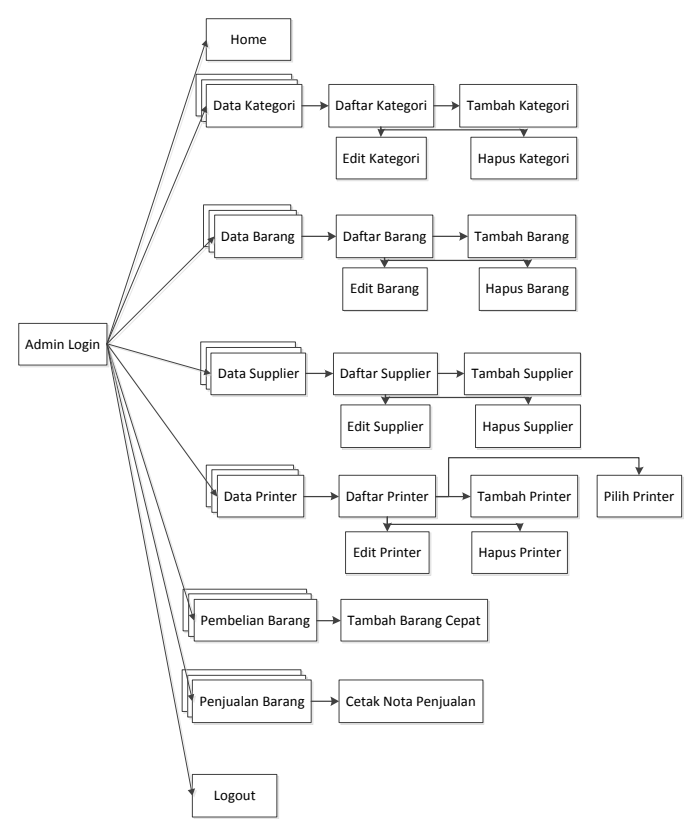

Gambar 5. Pembagian menu super kasir

c. Menu Admin

Pada gambar 6, berikut ditampilkan menu yang akan didapatkan oleh Admin.

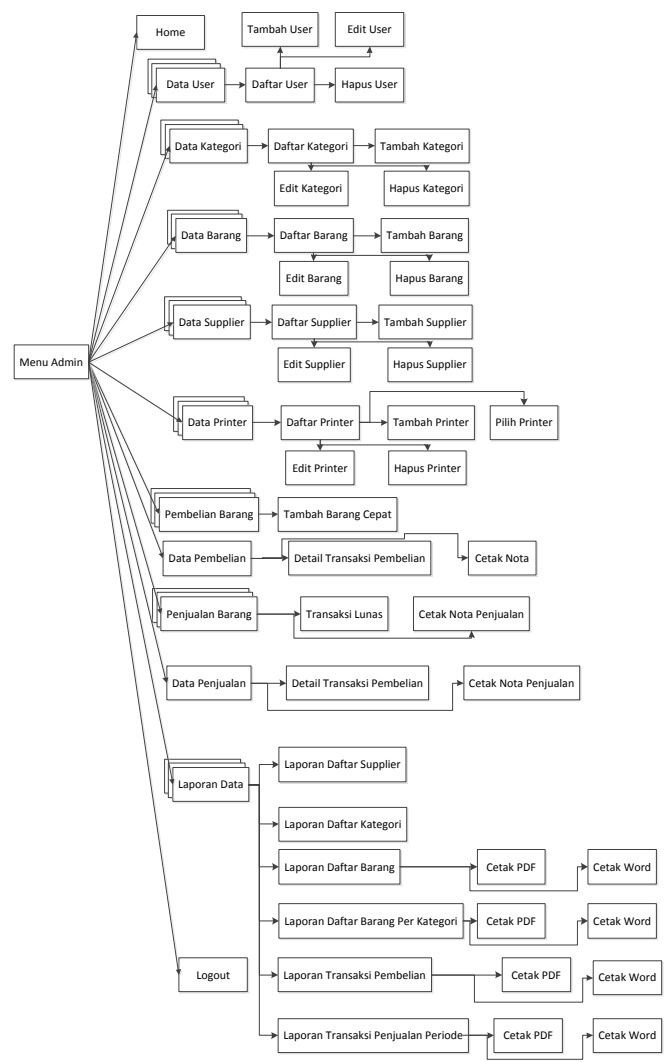

Gambar 6. Pembagian menu admin

\section{IMPLEMENTASI DAN PENGUJIAN SISTEM}

\section{A. Implementasi}

Tahap implementasi sistem merupakan tahap menerjemahkan perancangan berdasarkan hasil analisa dalam bahasa yang dapat dimengerti oleh mesin serta penerapan perangkat lunak pada keadaan yang sesungguhnya.Antarmuka yang digunakan dalam sistem pemrosesan transaksi toko bangunan berbasis web memiliki tampilan sebagai berikut

1. Menu Admin

Tampilan login user dapat dilihat pada Gambar 7. berikut.

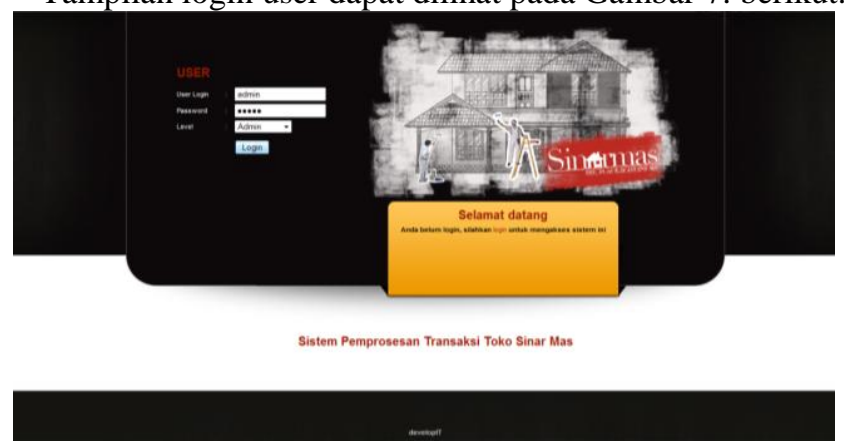

Gambar 7. Tampilan saat login 
Tampilan menu "Admin" dapat dilihat pada Gambar 8 berikut.

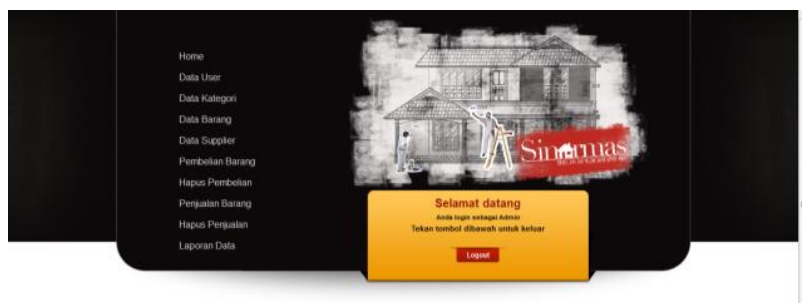

Sistem Pemprosesan Transaksi Toko Sinar Mas

Gambar 8. Tampilan menu admin

Tampilan menu "SuperKasir" dapat dilihat pada Gambar 9 berikut.
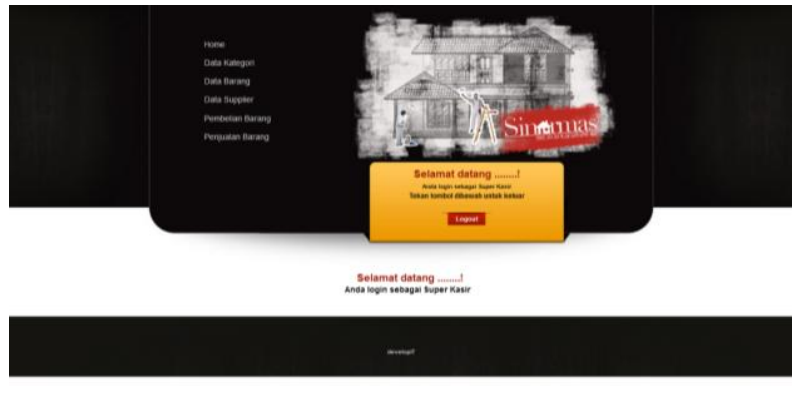

Gambar 9. Tampilan menu superkasir

Tampilan menu "Kasir" dapat dilihat pada Gambar 10. berikut.
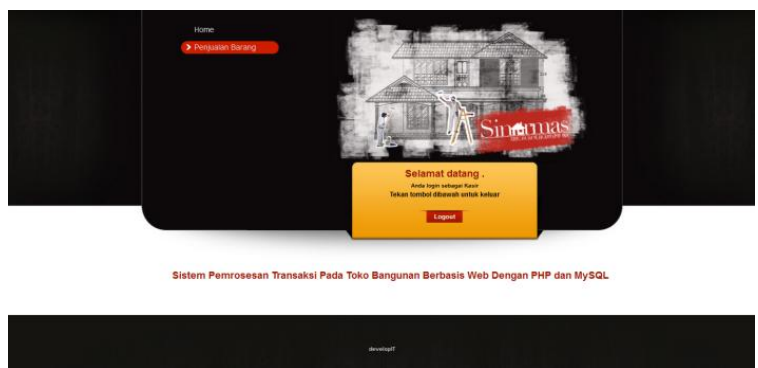

Gambar 10. Tampilan menu kasir

\section{B. Pengujian}

Proses pengujian menggunakan metode black-box dibagi menurut fungsi dari masing-masing menu sesuai dengan kegunaannya. Bentuk pengujian berupa cara pengguna menggunakan aplikasi.

Pengujian dimulai dengan pengujian menu login yang merupakan pintu utama untuk menggunakan fasilitas yang disediakan oleh aplikasi. Untuk melihat pengujian keseluruhan sistem dapat dilihat pada tabel 1. berikut.

Tabel 1. Pengujian sistem

\begin{tabular}{|l|l|}
\hline \multicolumn{1}{|c|}{ Nama Pengujian } & Hasil Pengujian \\
\hline Pengujian menu data user. & Berhasil. \\
\hline Pengujian menu tambah akun. & Berhasil \\
\hline Pengujian menu edit akun & Berhasil \\
\hline Pengujian menu menghapus akun & Berhasil \\
\hline Pengujian menu data kategori barang. & Berhasil. \\
\hline Pengujian menu tambah kategori barang. & Berhasil \\
\hline
\end{tabular}

Tabel 1. Pengujian sistem (lanjutan)

\begin{tabular}{|c|c|}
\hline Nama Pengujian & Hasil Pengujian \\
\hline Pengujian menu edit kategori barang. & Berhasil \\
\hline Pengujian menu menghapus kategori barang. & Berhasil \\
\hline Pengujian menu data barang. & Berhasil. \\
\hline Pengujian menu tambah barang. & Berhasil \\
\hline Pengujian menu edit barang. & Berhasil \\
\hline Pengujian menu menghapus barang. & Berhasil \\
\hline Pengujian menu data supplier. & Berhasil. \\
\hline Pengujian menu tambah supplier. & Berhasil \\
\hline Pengujian menu edit data supplier. & Berhasil \\
\hline Pengujian menu menghapus supplier. & Berhasil \\
\hline Pengujian menu data printer. & Berhasil. \\
\hline Pengujian menu tambah printer. & Berhasil \\
\hline Pengujian menu edit data printer. & Berhasil \\
\hline Pengujian menu menghapus printer. & Berhasil \\
\hline Pengujian menu pilih printer & Berhasil \\
\hline Pengujian menu pembelian barang. & Berhasil \\
\hline Menambahkan kode barang cepat. & Berhasil \\
\hline $\begin{array}{l}\text { Pengujian menghapus transaksi pembelian pada } \\
\text { menu hapus pembelian. }\end{array}$ & Berhasil \\
\hline Pengujian menu penjualan barang. & Berhasil \\
\hline $\begin{array}{l}\text { Pengujian menghapus transaksi penjualan pada } \\
\text { menu hapus penjualan. }\end{array}$ & Berhasil \\
\hline Pengujian menu laporan. & Berhasil \\
\hline Pengujian sub menu laporan supplier. & Berhasil \\
\hline Pengujian sub menu laporan kategori barang. & Berhasil \\
\hline Pengujian sub menu laporan barang. & Berhasil \\
\hline $\begin{array}{l}\text { Pengujian cetak laporan dalam PDF sub menu } \\
\text { laporan barang. }\end{array}$ & Berhasil \\
\hline $\begin{array}{l}\text { Pengujian cetak laporan dalam Word sub menu } \\
\text { laporan barang. }\end{array}$ & Berhasil \\
\hline Pengujian sub menu laporan barang per kategori. & Berhasil \\
\hline $\begin{array}{l}\text { Pengujian cetak laporan dalam PDF sub menu } \\
\text { laporan barang per kategori. }\end{array}$ & Berhasil \\
\hline $\begin{array}{l}\text { Pengujian cetak laporan dalam Word sub menu } \\
\text { laporan barang per kategori. }\end{array}$ & Berhasil \\
\hline $\begin{array}{lllll}\begin{array}{l}\text { Pengujian sub } \\
\text { pembelian. }\end{array} & \text { menu laporan } & \text { transaksi } \\
\end{array}$ & Berhasil \\
\hline $\begin{array}{l}\text { Pengujian cetak laporan dalam PDF sub menu } \\
\text { laporan transaksi pembelian. }\end{array}$ & Berhasil \\
\hline $\begin{array}{l}\text { Pengujian cetak laporan dalam Word sub menu } \\
\text { laporan transaksi pembelian. }\end{array}$ & Berhasil \\
\hline $\begin{array}{lcccc}\begin{array}{l}\text { Pengujian sub } \\
\text { penjualan. }\end{array} & \text { menu laporan } & \text { transaksi } \\
\end{array}$ & Berhasil \\
\hline $\begin{array}{l}\text { Pengujian cetak nota per transaksi sub menu } \\
\text { laporan transaksi penjualan. }\end{array}$ & Berhasil \\
\hline $\begin{array}{lll}\begin{array}{l}\text { Pengujian sub menu laporan } \\
\text { penjualan per periode. }\end{array} & \text { transaksi } \\
\end{array}$ & Berhasil \\
\hline $\begin{array}{l}\text { Pengujian cetak laporan dalam PDF sub menu } \\
\text { laporan transaksi penjualan per periode. }\end{array}$ & Berhasil \\
\hline $\begin{array}{l}\text { Pengujian cetak laporan dalam Word sub menu } \\
\text { laporan transaksi penjualan per periode. }\end{array}$ & Berhasil \\
\hline Pengujian sub menu laporan daftar petugas. & Berhasil \\
\hline Pengujian keluar dari sistem. & Berhasil \\
\hline
\end{tabular}

\section{KESIMPULAN DAN SARAN}

\section{A. Kesimpulan}

Dari hasil pengujian dan analisis aplikasi Sistem Pemrosesan Transaksi pada toko bangunan maka dapat disimpulkan hal-hal sebagai berikut.

1. Sistem pemrosesan transaksi ini dirancang sesuai dengan penelitian yang telah dilakukan di toko bangunan Sinar Mas.

2. Sistem pemrosesan transaksi ini berfungsi untuk mendata barang dan supplier, selain itu juga digunakan untuk menyimpan transaksi penjualan, pembelian dan membuat laporan.

3. Sistem pemrosesan transaksi ini menggunakan pembayaran secara lunas untuk transaksi penjualan.

4. Sistem pemrosesan transaksi ini menggunakan PDF dan Word untuk mencetak laporan. 


\section{B. Saran}

Berdasarkan pengujian terhadap sistem pemrosesan transaksi yang telah dibuat, dapat diberikan beberapa saran sebagai berikut.

1. Sistem pemrosesan transaksi ini dapat dikembangkan lebih lanjut dengan menambahkan beberapa fitur yang belum dimasukkan ke dalam aplikasi agar sistem pemrosesan transaksi ini memiliki fitur yang lebih lengkap.

2. Perlu dilakukan pelatihan kepada operator sistem pemrosesan transaksi ini agar mengetahui fungsi-fungsi sistem ini dan dapat menggunakannya dengan baik.

\section{Daftar Pustaka}

1. Al-Bahra, 2005, "Analisis dan Desain Sistem Informasi”, Yogyakarta: Graha Ilmu.

2. Bunafid Nugroho, 2004, "PHP \& mySQL dengan Editor Dreamweaver MX", Yogyakarta: Penerbit Andi.

3. Hanif Al Fatta, 2007, "Analisis dan Perancangan Sistem Informasi untuk Keunggulan Bersaing Perusahaan dan Organisasi Modern", Jogjakarta: Andi Offset.

4. Ian Sommerville, 2001, "Software Engineering, 6th Edition “, Boston, Massachusetts: Pearson Education, 2001.

5. Ian Sommerville, "Software Engineering, 9th Edition." Boston, Massachusetts: Pearson Education, 2011.
6. Peranginangin, Kasiman. 2006. Aplikasi WEB dengan PHP dan MySQL, Yogyakarta: Andi.

7. Pressman, Roger S, 2002, "Rekayasa Perangkat Lunak: Pendekatan Praktisi (Buku I)", Yogyakarta: Penerbit Andi.

8. Turban, E., Leidner, D., Mclean, E., \& Wetherbe, J.,2008, "Information Technology for Management: Transforming Organization in the Digital Economy". John Wiley \& Sons, Inc.

9. Yakub, 2008, "Sistem Basis Data Tutorial Konseptual", Yogyakarta: Penerbit Graha Ilmu.

10. Yeni Kustiyahningsih, 2011, "Pemrograman Basic Data Berbasis Web Menggunakan PHP \& SQL", Bangkalan: Graha Ilmu.

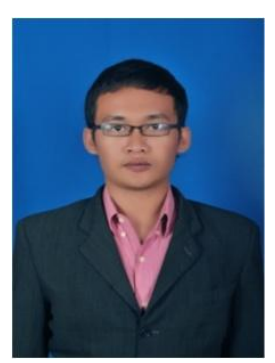

Rizky Gelar Maliq (L2N009086). Lahir di Ambarawa 26 November 1990. Bersekolah di SD Sudirman II Ambarawa dan di SMPN II Ambarawa, lalu melanjutkan di SMK Telkom Shandy Putra Purwokerto dan kini menempuh pendidikan Strata satu di Program studi Sistem Komputer Fakultas Teknik Universitas Diponegoro. 